\title{
Drug Resistance Pattern of $M$. tuberculosis Complex in Oromia Region of Ethiopia
}

\author{
Hussien Bedru (D) \\ Melaku Fikru² \\ Wardofa Niguse ${ }^{2}$ \\ Aman Jemal ${ }^{2}$ \\ Garoma Getinet ${ }^{2}$ \\ Ameni Gobena $\mathbb{D D}^{3,4}$ \\ Awraris Hailu (iD ${ }^{5}$ \\ Sandy Peter 6 \\ 'Department of Public Health, Goba \\ Referral Hospital, Madda Walabu \\ University, Goba, Oromia Region, Ethiopia; \\ ${ }^{2}$ Tuberculosis Unit, Adama Public Health \\ Research Laboratory, Oromia Health \\ Bureau, Adama, Oromia Region, Ethiopia; \\ ${ }^{3}$ Aklilu Lemma Institute of Pathobiology, \\ Addis Ababa University, Addis Ababa, \\ Ethiopia; ${ }^{4}$ Department of Veterinary \\ Medicine, College of Food and Agriculture, \\ United Arab Emirates University, Al Ain, \\ United Arab Emirates; ${ }^{5}$ Department of \\ Public Health, Debre Birhan University, \\ Debre-Birhan, Ethiopia; ${ }^{6}$ Department of \\ Health Studies, University of South Africa, \\ Pretoria, South Africa
}

Purpose: Multidrug resistant tuberculosis is an emerging problem in many parts of the world. The aim of this study was to determine the drug resistance pattern of Mycobacterium tuberculosis complex in Oromia Region of Ethiopia.

Patients and Methods: A cross-sectional study was conducted from Jan 2017 to June 2018 on 450 pulmonary tuberculosis patients who visited health facilities in nine administrative zones of Oromia Region. Socio-demographic characteristics and relevant clinical information were obtained using a structured questionnaire. Line Probe Assay for first and second line drugs was used to assess the pattern of drug resistance. SPSS version 20 was used for statistical analysis. Results: Median age was 26 years and 240 (53.3\%) patients were males. About 24\% of them were previously treated for tuberculosis. Thirty-four (7.6\%) were HIV co-infected. Line Probe Assay interpretable results were obtained for 387 isolates. Thirty (7.8\%) were resistant to rifampicin and isoniazid and thus were multidrug resistant isolates. Among the multidrug resistant samples, three were found to be extensively drug resistant and one was preextensively drug resistant. Previous treatment history (AOR 9.94 (95\% CI 3.73-26.51), $P<0.001$ ) and nutritional status below normal (AOR 3.15 (95\% CI 1.13-8.81), $P<$ 0.029 ) were found to be associated with multidrug resistance. The chi-square tests have shown that there was a significant difference between the BCG vaccinated and the nonvaccinated in developing multidrug resistant tuberculosis at $P=0.027$.

Conclusion: The proportion of multidrug resistance is above the WHO estimate for the country, Ethiopia, and the fact that some zones were at risk of transmission of extensively drug resistant tuberculosis warrant great attention of the control program holders even though it has to be verified through the conventional method.

Keywords: line probe assay, multidrug resistant tuberculosis, extensively drug resistant tuberculosis, Oromia

\section{Introduction}

Tuberculosis (TB) is a worldwide problem. Ethiopia is one of the 30 high TB burden countries with the best estimate of incidence of 165,000 cases with HIV positive TB incidence of 7600 and HIV prevalence in incident TB cases of $4.6 \%$ in 2018. The emergence of resistant strains of Mycobacterium tuberculosis (MTB) has created a major threat to the control of TB. ${ }^{1,2}$ Ethiopia is now one of the 30 high multidrug resistant/Rifampicin resistant-TB (MDR/RR-TB) burden countries as well and the level of MDR/RR-TB in Ethiopia shows an increasing trend which still calls for serious intervention. ${ }^{2,3}$

Estimation of the actual prevalence of extensively drug resistant TB (XDR-TB) or pre-XDR cases in Ethiopia is not yet well known; ${ }^{3}$ therefore, $0.71 \%$ of new TB
Correspondence: Hussien Bedru Goba Referral Hospital, P.O.Box: 302 Tel +251911997287

Fax +25I2266I-0I64

Email bedru1964@gmail.com 
cases and $16 \%$ previously treated MDR/RR-TB cases notified in the reporting year of 2018 are used as estimated burden of resistance to anti TB drugs. ${ }^{2}$ Moreover, due to the lack of national capacity to perform universal drug sensitivity testing (DST) for all incident TB cases, it is difficult to secure early diagnosis and administration of appropriate therapy in quite significant number of health facilities. ${ }^{4}$

According to the World Health Organization (WHO) Global TB Report of 2019, estimated TB mortality rate of Human Immune-deficiency Virus (HIV) negative cases in 2018 for Ethiopia was $20-39$ per $100,000 .^{2}$ Though the contribution of HIV infection in TB patients to the development of anti-TB drug resistance is not clear, in recent years, infection with HIV denotes a major risk factor predisposing for opportunistic infections and $\mathrm{TB}$ is the most common cause of acquired immune-deficiency syndrome (AIDS) related deaths. ${ }^{5}$ Drug resistance in TB is a matter of great concern for TB control programs because resistant strains could spread around the world, stressing the need for additional control measures, such as new diagnostic methods, better drugs for treatment, and a more effective vaccine. ${ }^{6-9}$ The need for additional control measures, on top of the problems related to the prevalence of drug susceptible TB, is one of the health priorities which may compromise the progress of other development agenda of the country.

To contain the spread of drug resistant tuberculosis, early detection of resistance of any kind (RR, MDR, or XDR is crucial when resistance is suspected to decide on the timely management of a TB case and this necessitates the use of newer diagnostic methods for DST. ${ }^{10-12}$ It is also important to know a drug resistance pattern of a certain area to take appropriate action in the prevention and management of TB for an effective control program. ${ }^{13,14}$

The purpose of this study was to determine the drug resistance pattern of MTB strains isolated from smearpositive pulmonary TB patients in Oromia, the biggest region of the country, to indicate the importance of appropriate action as a public health measure and to contribute to the effective control of resistant tuberculosis.

\section{Patients and Methods}

\section{Study Design, Area, Period, and Setting}

Health institution-based repeated cross-sectional design was used in order to perform the present study. Oromia region, the study area, is one of the 10 regional states of the Federal Republic of Ethiopia with a population of about 40 million. In 2017, the region is divided into 22 administrative zones, 19 town administrations, and 337 woredas (sub zones). There were 112 hospitals, 1405 health centers, 5930 health posts. Data were collected during the period between January, 2017 and June, 2018.

\section{Study Population and Subjects}

Individuals visiting health centers and hospitals located in nine zones of the Oromia Regional State for ill health and were diagnosed with pulmonary TB constitute the study population.

\section{Sampling Method and Sample Size}

It was decided to include nine zones, 21 sub zones, and 32 health facilities to recruit 450 study participants. Study participants were selected according to their arrival for clinical consultation until the estimated sample size was obtained. The sample size was determined based on the resource available, accessibility of health facilities, population size of the study area, and sample size of previous studies on drug resistance patterns in the neighboring regions.

\section{Inclusion Criteria}

Patients who were considered to be study participants have fulfilled the following requirements: Newly diagnosed pulmonary TB, volunteer to give consent or assent through guardian and permanently residing in the study area.

\section{Exclusion Criteria}

Patients with the following characteristics were excluded from the study: Being on anti-TB treatment for more than 2 weeks, admission to hospital (to not expose data collectors to the in-patient environment), and permanent address out of the study area.

\section{Data Collection Instrument and Process Development and Testing of the Data Collection Instrument}

The data collection instrument was developed after reviewing methodologies of several relevant literatures and considering the research questions to be answered. In this regard, structured, prepared in English language and pretested interviewer administered questionnaires were used to collect data on basic socio-demographic characteristics as well as clinically relevant factors after a case is labeled as pulmonary TB by a clinician based on the National TB and Leprosy Control Program Guideline. ${ }^{15}$ 


\section{Interview}

After informed consent, questionnaires were administered by the trained data collectors in local language. The data collectors were skilled laboratory technicians, nurses, or public health workers.

\section{Sputum Collection}

Each eligible client was instructed to bring morning sputum $(3-5 \mathrm{~mL})$ in a sterile plastic tube of $50 \mathrm{~mL}$ capacity (falcon tubes) prepared for this purpose. Sputum samples were collected by the laboratory staff and were shared between the diagnostic and research teams. Then stored in the health facility's laboratory for a maximum of 2 days in a temperature range of $2-8{ }^{\circ} \mathrm{C}$ until transported to Adama Public Health Research Laboratory (APHRL) for culture and DST. Sputa were collected before chemotherapy is started or at least not beyond two weeks of treatment because treatment can reduce the chance of having a positive culture result for tubercle bacilli.

\section{Sample Transportation and Storage}

Samples were transported under triple package in ice pack carriers maintaining the cold chain to the APHRL until the required number of samples was obtained. The preparation and packing of the specimen complied with the national standard operating procedures for biological sample transportation. ${ }^{16}$ The triple packaged samples with participant data were transported to the APHRL through the sample transportation (postal) system within a maximum of three days after the sputa collection.

\section{Staining, Culture, and Identification}

Staining of Acid Fast Bacilli (AFB), Ziehl-Neelsen (ZN) staining was done for every sample to be cultured to confirm the sputum smear positivity according to WHO guideline. ${ }^{17}$

\section{Sputum Culture}

Samples that were found to be smear-positive with ZN staining method were cultured on to Lowenstein Jensen (LJ) and Mycobacterial Growth Indicator Tube (MGIT) media according to the WHO guideline. ${ }^{18}$

The LJ medium culture was incubated at $37{ }^{\circ} \mathrm{C}$ and read weekly for eight weeks. Positive results were determined weekly and if there is no growth at the end of 8th week, the result was considered negative. Contaminated cultures were recorded as "contaminated" in the laboratory form.

MGIT was incubated in Middle Brook 7H9 medium on MGIT machine and the result was flagged as negative or positive on the machine. MGIT positive cultures were tested on blood agar and ZN staining to assess if contaminants exist.

\section{Identification of Mycobacterium tuberculosis Complex} An immune-chromatographic assay (Capila ${ }^{\mathrm{TM}}$ TB-Neo version 6.0. Tauns Laboratories, Inc. Japan $)^{19}$ was used to differentiate MTB complex (MTBC) from nontubercular mycobacteria (NTM). It can detect the antigens designated as MPB64 in bacterial isolates specifically produced by the MTBC with a high degree of sensitivity, and provides rapid test results (in less than an hour) by a simple operation. H37Rv (ATCC27294) was used as positive control in each set of tests.

\section{Drug Sensitivity Testing}

\section{Line Probe Assays (LPA) for First Line Drugs}

First line LPA DST was done for all isolates identified as MTBC using Geno Type MTB DR/plus VER 2.0. ${ }^{20}$ LPA is based on deoxyribonucleic acid (DNA) strip technology and was done in three steps. First, DNA was extracted from MTB isolates. Next polymerase chain reaction (PCR) amplification was carried out using biotinylated primers. Following amplification, DNA was hybridized with specific oligonucleotide probes immobilized on a strip which enables the detection of the presence of MTB, and the presence of wild-type (WT) and mutation probes for resistance to rifampicin and isoniazid simultaneously.

\section{Interpretation}

Results were interpreted with the use of reading card. There were three internal controls (CC - conjugation control, HYB; AC - Amplification control MM and amplification program; TUB-MTBC, TB positive or negative) and WT probes. Where all the controls and WT were present, sensitivity declared. Where one or more wild types were missing or one or more wild types were missing with a correlating mutation, resistance was documented.

\section{LPA for Second Line Drugs}

Those isolates which were turned out to be MDR (resistant to at least rifampicin and isoniazid) or RR were subjected to second line LPA. Drugs involved were capreomycin, amikacin, kanamycin and viomycin from the injectable, and fluoroquinolones from the oral second line drugs. Molecular genetic assay for identification of the MTBC and its resistance to aminoglycosides/cyclic peptides and fluoroquinolones was performed on cultivated samples according to GenoType MTBDRsl VER 2.0 instruction 
for use. ${ }^{21}$ The positive control, DNA obtained from the standard H37RV strain and one negative control was also tested in each batch in order to check the crosscontamination during hybridization.

\section{Evaluation and Interpretation}

The test was considered valid, only when the hybridization bands were obtained on MTBC control (TUB), conjugate controls (CC) and the amplification controls (AC) along with the targeted gene loci controls. ${ }^{22}$ There are also WT reaction zones which comprise regions of the genome with known resistance mutations and the MUT reaction zones corresponding to probes that identify the most common resistance mutations of the gene cross-examined. If a WT band was missing or if a MUT band was present, it was taken as an indication of a resistant strain. The resistance status was determined and noted down in the respective column. However, possibility of mutations (resistance) of the strains outside the regions covered by the test cannot be ruled out.

\section{Statistical Analysis}

The statistical analysis was performed using SPSS version 20. Descriptive statistics were used to depict the sociodemographic, clinical history, and nutritional status. Bivariate and multiple logistic regression models as well as Chi- square tests were used to test for possible associations between variables.

\section{Operational Definitions}

MDR isolate: Is an isolate that is found to be resistant to at least isoniazid and rifampicin.

New TB case: Smear-positive pulmonary TB patient who has never taken anti-TB drugs or has been on TB drug treatment for less than four weeks in previous episode.

Previously treated TB case: Is a patient who has a history of anti-TB drug treatment for at least four weeks for previous episode.

Pre-XDR isolate: Is an isolate that is MDR plus resistant to at least one of the fluoroquinolones (levofloxacin, moxifloxacin, ofloxacin, ciprofloxacin, gemifloxacin) or at least to one of the second-line injectable agents (kanamycin, amikacin, capreomycin).

RR isolate: Is an isolate that is resistant to rifampicin but not to isoniazid with or without being resistant to any other anti-TB drugs.
XDR isolate: Is an isolate that is MDR plus resistant to at least one of the fluoroquinolones and at least to one of the second-line injectable.

\section{Results}

\section{Socio-Demographic Characteristics of the Study Participants}

The socio-demographic data of the study patients is presented in Table 1. A total of 450 patients were recruited into the study. The majority of the study participants were within the age group of 18-28 years. The age range and median age were 4-81 years and 26 years respectively. The sex composition was approximately equal. Geographically, more than two-thirds of the study population (68\%) were from East-Shewa, Arsi, Bale and Guji zones in decreasing order. Patients who were not able to read and write and those who were farmers living in rural areas dominate the study population. More than a quarter of the patients live in a house with no window and yet the majority of the participants use wood, cow dung, and/or charcoal for cooking. About one third of them have a family size of greater than four and a similar number of them have only one room to live in.

\section{Information Pertaining to Clinical History of the Patients}

According to the clinical information obtained from the patients, a quarter of them were previously treated as pulmonary TB patients for at least 4 weeks but were currently having a similar episode. Of the previously treated cases, more than half of them were not cured of the last previous episode while about three fourths of them had developed the symptoms again within one year. Of the total patients, quite a significant proportion of the patients sought modern treatment after about 4 weeks of symptoms; but some of them tried traditional medicine. History of close contact to known TB cases or chronic coughers and HIV serum positivity were documented in some patients. More than half of all the subjects had fallen within the under-nutrition range of body mass index and very few of them were overweight (Table 2).

\section{Drug Sensitivity Testing}

Sensitivity Pattern to Isoniazid and Rifampicin

Of all the 450 smear positive samples collected from the study sites and cultured on both LJ and MGIT media 402 
Table I Socio-Demographic Characteristics of the Study Participants, $n=450$, Oromia, 2020

\begin{tabular}{|c|c|c|}
\hline Characteristics & & N (\%) \\
\hline \multirow[t]{5}{*}{ Age (years) } & $<18$ & $52(11.6)$ \\
\hline & $18-28$ & $203(45.1)$ \\
\hline & $29-39$ & $106(23.6)$ \\
\hline & $40-45$ & $55(12.2)$ \\
\hline & $>50$ & $34(7.6)$ \\
\hline \multirow[t]{2}{*}{ Sex } & Male & $240(53.3)$ \\
\hline & Female & $210(46.7)$ \\
\hline \multirow[t]{9}{*}{ Address (Zones) } & North Shewa & $37(8.2)$ \\
\hline & South West Shewa & $28(6.2)$ \\
\hline & East Shewa & $92(20.4)$ \\
\hline & Arsi & $88(19.6)$ \\
\hline & West Arsi & $24(5.3)$ \\
\hline & Bale & $64(14.2)$ \\
\hline & Guji & $60(13.3)$ \\
\hline & Borena & $25(5.6)$ \\
\hline & West Harerge & $32(7.1)$ \\
\hline \multirow[t]{5}{*}{ Education status } & Cannot read and write & $169(37.6)$ \\
\hline & Read and write & $88(19.6)$ \\
\hline & Elementary school & $146(32.4)$ \\
\hline & Secondary school & $31(6.9)$ \\
\hline & College and above & $16(3.6)$ \\
\hline \multirow[t]{5}{*}{ Occupation } & Farmer & $160(35.6)$ \\
\hline & Merchant & $17(3.8)$ \\
\hline & Government employee & $10(2.2)$ \\
\hline & Student & $84(18.2)$ \\
\hline & Others** & $178(39.6)$ \\
\hline \multirow[t]{3}{*}{ Residence } & Urban & I74(38.7) \\
\hline & Semi-urban & $21(4.7)$ \\
\hline & Rural & $255(56.7)$ \\
\hline \multirow[t]{3}{*}{ Window } & Yes & $318(70.7)$ \\
\hline & No & $128(28.4)$ \\
\hline & Homeless & $4(0.9)$ \\
\hline \multirow[t]{4}{*}{ Source of energy } & Wood cow-dung charcoal & $435(96.7)$ \\
\hline & Kerosene & $4(0.9)$ \\
\hline & Electricity & $8(1.8)$ \\
\hline & None & $3(0.9)$ \\
\hline \multirow[t]{3}{*}{ Family size } & Lives alone & $10(2.2)$ \\
\hline & $\mathrm{I}-4$ & $298(66.2)$ \\
\hline & $>4$ & $142(31.6)$ \\
\hline \multirow[t]{6}{*}{ Number of rooms } & No room & $4(0.9)$ \\
\hline & One & $159(35.3)$ \\
\hline & Two & $232(51.6)$ \\
\hline & Three & $42(9.3)$ \\
\hline & Four & II (2.4) \\
\hline & Five & $2(0.4)$ \\
\hline
\end{tabular}

(Continued)
Table I (Continued).

\begin{tabular}{|l|l|c|}
\hline Characteristics & & N (\%) \\
\hline Number of meals per day & Three and above & $380(84.4)$ \\
& Less than three & $13(2.9)$ \\
& No regular meal & $57(12.7)$ \\
\hline
\end{tabular}

Notes: Others** indicates housewife, Daily laborer, or jobless.

Table 2 Clinical Information Obtained from Pulmonary Tuberculosis Patients, Oromia, 2020

\begin{tabular}{|c|c|c|}
\hline Clinical Characteristics & Numbe & (\%) \\
\hline $\begin{array}{l}\text { Category of tuberculosis treatment } \\
\text { history }\end{array}$ & $\begin{array}{l}\text { New } \\
\text { Prev treated }\end{array}$ & $\begin{array}{l}343(76.2) \\
107(23.8)\end{array}$ \\
\hline $\begin{array}{l}\text { Duration of adherence to treatment } \\
\text { after } 4 \text { wks } \\
(n=107)\end{array}$ & $\begin{array}{l}<6 \mathrm{mo} \\
>\text { or= 6mo } \\
\text { Unknown }\end{array}$ & $\begin{array}{l}55(51.4) \\
46(43.0) \\
6(5.6)\end{array}$ \\
\hline $\begin{array}{l}\text { Treatment outcome of prev treated } \\
(\mathrm{n}=107)\end{array}$ & $\begin{array}{l}\text { Cured } \\
\text { Not cured } \\
\text { Unknown }\end{array}$ & $\begin{array}{l}42(39.3) \\
59(55.1) \\
6(5.6)\end{array}$ \\
\hline $\begin{array}{l}\text { Historyofclosecontactwithchronic } \\
\text { cougher }\end{array}$ & $\begin{array}{l}\text { No } \\
\text { Yes }\end{array}$ & $\begin{array}{l}368(81.8) \\
82(18.2)\end{array}$ \\
\hline $\begin{array}{l}\text { Duration of illness before medical } \\
\text { treatment }\end{array}$ & $\begin{array}{l}<\mathrm{Imo} \\
\mathrm{I}-2 \mathrm{mo} \\
>2 \mathrm{mo}\end{array}$ & $\begin{array}{l}137(30.4) \\
225(50.0) \\
88(19.6)\end{array}$ \\
\hline Used traditional medicine & $\begin{array}{l}\text { No } \\
\text { Yes }\end{array}$ & $\begin{array}{l}397(88.2) \\
53(11.8)\end{array}$ \\
\hline HIV serum status & $\begin{array}{l}\text { Negative } \\
\text { Positive } \\
\text { Unknown }\end{array}$ & $\begin{array}{l}404(89.8) \\
34(7.6) \\
12(2.6)\end{array}$ \\
\hline BCG vaccination status & $\begin{array}{l}\text { Not Vaccinated } \\
\text { Vaccinated } \\
\text { Do not } \\
\text { remember }\end{array}$ & $\begin{array}{l}322(71.6) \\
112(24.9) \\
16(3.6)\end{array}$ \\
\hline Nutritional status (BMI*) & $\begin{array}{l}\text { Severe UW } \\
\text { Moderate UW } \\
\text { Mild UW } \\
\text { Normal } \\
\text { Overweight }\end{array}$ & $\begin{array}{l}40(8.9) \\
52(\mid I .6) \\
140(31.1) \\
213(47.3) \\
5(I . I)\end{array}$ \\
\hline
\end{tabular}

Abbreviations: BMI*, body mass index; UW, underweight.

(89.3\%) were successfully grown while $48(10.7 \%)$ were either contaminated or culture negative. All the culture positive isolates were examined by Tauns Capilia tuberculosis-Neo Test for species identification and 6 were found to be NTM and excluded. In the first round, the remaining 
396 samples were tested using LPA to the two main first line drugs, isoniazid and rifampicin. Of these 396 isolates tested using LPA, invalid test results were obtained for nine while interpretable results were obtained for 387 isolates; 350 of them were susceptible to both drugs, seven $(1.8 \%)$ were resistant to either rifampicin (3 isolates) or isoniazid (4 isolates) while the remaining 30 (7.8\%) were resistant to both drugs and thus were MDR isolates. Highest percentage of MDR-TB was observed among the age group of 18 to 39 . Over $60 \%$ of the MDR was observed in four of the nine zones. These include East Shewa, West Arsi, Bale and West Harerge (Table 3). Among the previously treated and those who were not cured and whose DST results were available, 17/44 (38.6\%) were found to be MDR cases. It was only 4 out of $35(11.4 \%)$ in the cured ones. Only 47 patients reported the use of traditional medicine of any kind and 2 of them became MDR cases on DST.

\section{Sensitivity Pattern of MDR/RR-TB Cases to Second Line Anti-TB Drugs}

The cases found to be MDR-TB with LPA (Geno-Type MTBDRplus Version 2.0) and the three RR cases were further tested for the second line drugs using LPA (Geno-Type MTBDRsl Version 2.0). As a result, among the 30 MDR isolates, three of them were found to be extensively drug resistant (XDR) and one was pre-XDR. Out of the 33 cases (MDR and RR) tested for second line drugs, 23 (69.7\%) were sensitive to all the second line drugs tested. One of the three RR but sensitive to isoniazid was resistant to all second line drugs (poly-resistant), the second one was sensitive to all (mono-resistant), and the third one was sensitive only to fluoroquinolones (poly-resistant). Some of the characteristics of patients with XDR-TB are described in Table 4.

Bivariate logistic regression model analysis depicts no statistical association at $p$-value $<0.25$ between multidrug resistance and age, sex, education, occupation, residence, and HIV serum status. On the other hand, being previously treated, having a history of close contact with a chronic cougher, staying more than two months after onset of illness without getting medical treatment, and nutritional status of under-nutrition were tested for association using multiple logistic regression following bivariate analysis and previous treatment history (AOR 9.94 (95\% CI 3.73-26.51), $P<0.001$ ) and nutritional status below normal (AOR 3.15 (95\% CI 1.13-8.81), $P<0.029)$ were found to be associated with multidrug resistance (Table 5).
Table 3 Distribution of MDR by Patient Characteristics, $(n=387)$, Oromia, 2020

\begin{tabular}{|c|c|c|c|}
\hline & $\begin{array}{l}\text { Non- } \\
\text { MDR-TB } \\
\text { Number }\end{array}$ & $\begin{array}{l}\text { MDR-TB } \\
\text { Number (\%) }\end{array}$ & Total \\
\hline Total & 357 & $30(7.8)$ & 387 \\
\hline \multicolumn{4}{|l|}{ Age group (years) } \\
\hline$<18$ & 45 & $0(0)$ & 45 \\
\hline $18-28$ & 157 & $15(8.7)$ & 172 \\
\hline $29-39$ & 82 & $10(10.9)$ & 92 \\
\hline $40-50$ & 48 & $3(5.9)$ & 51 \\
\hline$>50$ & 25 & $2(7.4)$ & 27 \\
\hline \multicolumn{4}{|l|}{ Sex } \\
\hline Male & 195 & $17(8.0)$ & 212 \\
\hline Female & 162 & $13(7.4)$ & 175 \\
\hline \multicolumn{4}{|l|}{ Zone } \\
\hline North Shewa & 29 & $2(6.4)$ & 31 \\
\hline South-West Shewa & 25 & I (3.8) & 26 \\
\hline East Shewa & 63 & $5(7.3)$ & 68 \\
\hline Arsi & 80 & $3(3.6)$ & 83 \\
\hline West-Arsi & 17 & $5(22.7)$ & 22 \\
\hline Bale & 41 & $5(10.9)$ & 46 \\
\hline Guji & 54 & $4(6.9)$ & 58 \\
\hline Borena & 23 & $0(0)$ & 23 \\
\hline West-Harerge & 25 & $5(16.7)$ & 30 \\
\hline \multicolumn{4}{|l|}{ Residence } \\
\hline Urban & 124 & $14(10.1)$ & 138 \\
\hline Semi-urban & 16 & $0(0)$ & 16 \\
\hline Rural & 217 & $16(6.9)$ & 233 \\
\hline \multicolumn{4}{|l|}{ Nutritional status } \\
\hline Severe under nutrition & 31 & $3(8.8)$ & 34 \\
\hline Moderate under nutrition & 41 & $6(12.8)$ & 47 \\
\hline Mild under nutrition & 96 & $14(12.7)$ & 110 \\
\hline Normal & 186 & $7(3.6)$ & 193 \\
\hline Over weight & 3 & $0(0)$ & 3 \\
\hline \multicolumn{4}{|l|}{ HIV status } \\
\hline Negative & 320 & $27(7.8)$ & 347 \\
\hline Positive & 27 & $3(10)$ & 30 \\
\hline Unknown & 10 & $0(0)$ & 10 \\
\hline \multicolumn{4}{|l|}{ Treatment history } \\
\hline New & 298 & $8(2.6)$ & 306 \\
\hline Previously treated & 59 & $22(27.1)$ & 81 \\
\hline
\end{tabular}

The chi-square tests have shown that there was an association between being MDR and no history of BCG vaccination at $P=0.027$ where the proportion of those who were not vaccinated and had MDR TB (10\%) was significantly greater than those who had a history of vaccination and had no MDR TB (2.1\%) (Table 6). 
Table 4 Description of Characteristics of the Patients with XDR-TB, Oromia, 2020

\begin{tabular}{|l|l|l|l|l|}
\hline & I & $\mathbf{2}$ & $\mathbf{3}$ & $\mathbf{4}$ \\
\hline Sam. code & BHI70 & BH302 & BH486 & BH303 \\
Age (yrs) & 22 & 35 & 34 & 24 \\
Sex & Male & Female & Male & Male \\
Zone & W/Harerge/Oda Bultum 3I & W/Harerge/Chiro & East Shewa/Bushoftu & Arsi/Robe Dide'a \\
Education & Rural & Rural & Urban & Rural \\
Occupation & Elementary & Cannot read and write & Elementary & Cannot read and write \\
Contact history & None & Farmer & Daily laborer & Farmer \\
Previous treatment & New & None & None & None \\
Nutritional status & Mildmalnutrition (UW) & Previously treated & Previously treated & New \\
HIV status & Negative & Negative & Moderate malnutrition (UW) & Normal \\
Resistance & XDR & XDR & Negative & Negative \\
\hline
\end{tabular}

\section{Discussion}

As described in the Results section out of 387 isolates for which DST was done using LPA, 350 of them were sensitive to first line drugs tested, rifampicin and isoniazid. Three isolates were resistant to rifampicin but sensitive to isoniazid and another four isolates were resistant to isoniazid but sensitive to rifampicin. The remaining 30 of the isolates were resistant to both rifampicin and isoniazid being labeled as MDR-TB. This was $2.6 \%$ in new cases and $27.1 \%$ in previously treated ones with the overall MDR prevalence rate of $7.8 \%$.

The 7.8\% MDR prevalence rate was not far from the results seen in a study done in Jijiga town, East Ethiopia with a sample size of 105 , which had the prevalence of MDR in new cases, in previously treated cases, and overall of $4.5 \%, 22.6 \%$ and $10.2 \%$ respectively. ${ }^{23}$ Another similar study in Jimma town, South West Ethiopia, with sample size of 112 shows an overall prevalence of MDR of $27.7 \%{ }^{24}$ Differences here might be explained by the fact that almost all $(106 / 112,94.6 \%)$ of the included isolates were having any resistance, patients were referred from health facilities probably after prior TB treatment. A similar study from Arsi zone of Oromia region, central Ethiopia with sample size of 150 , shows an MDR prevalence rate of $3.8 \%$ in new cases. ${ }^{25}$ This zone is one of the zones included in the current study and the overall MDR proportion out of 80 isolates examined was $3.6 \%$ which is similar to the finding. According to the surveillance of drug resistance based on reference laboratory data to the national level, ${ }^{26}$ among 329 isolates tested for first line drugs 5.7\% were isoniazid resistant, 6.3\% were rifampicin resistant, and MDR was documented in $4.3 \%$ of new cases and $6.7 \%$ of previously treated cases with the overall MDR proportion of $11.6 \%$. Given the difference in sampling technique and level of study between this surveillance and current study the differences observed in the findings is not out of expectation. In contrast to the current study the finding from southern Ethiopia shows an overall MDR-TB prevalence of 0.8 with no MDR-TB in new cases while it is $14.3 \%$ in previously treated cases and no XDR or pre-XDR cases. ${ }^{27}$ Similarly, reports from the Amhara region, North-West Ethiopia show that the overall proportion of MDR-TB was 5\% with $3.7 \%$ in new and $10.9 \%$ in previously treated cases but no report of XDRTB or pre-XDR-TB. ${ }^{28}$ One study from coastal Kenya also revealed an MDR-TB prevalence of $2.6 \%$ in new cases and $29.4 \%$ in previously treated cases. ${ }^{29}$ An MDR-TB prevalence of $5.3 \%$ in new and $14.7 \%$ in old cases was also reported from Sudan. ${ }^{30}$ Differences could be attributed to differences in methods used, sampling, or the innate existence of resistant cases or the combination of these factors. The global proportion of MDR/RR-TB was estimated to be $3.4 \%$ in new and $18 \%$ in previously treated cases while that of Ethiopia was $0.7 \%$ and $16 \%$ respectively. ${ }^{2}$ If we take this $\mathrm{WHO}$ report as a reference, though differences in the methods used exists, it is very likely that Oromia region takes the larger share of MDR/ RR-TB burden of the country.

Previously treated patients are those who were diagnosed to have TB and took anti-TB drugs for at least one month in the previous episode. These patients might or might not have completed the intended treatment; might have been declared cured or not. The proportion of previously treated patients was found to be significant; about $24 \%$. It is difficult to establish the reason why this is so 
Table 5 Patient Characteristics and Their Associations with Multidrug Resistance $(n=387)$, Oromia, 2020

\begin{tabular}{|c|c|c|c|c|c|c|c|c|c|}
\hline \multicolumn{2}{|c|}{ Characteristics } & \multirow{2}{*}{$\begin{array}{l}\text { Total } \\
45 \\
157 \\
82 \\
48 \\
25\end{array}$} & \multirow{2}{*}{$\begin{array}{l}\text { MDR } \\
0 \\
15 \\
10 \\
3 \\
2\end{array}$} & \multirow{2}{*}{$\begin{array}{l}\text { COR } \\
- \\
0.78 \\
1 \\
0.51 \\
0.66\end{array}$} & \multirow{2}{*}{$\begin{array}{l}95 \% \mathrm{Cl} \\
0.33-1.8 \\
0.13-1.93 \\
0.14-3.20\end{array}$} & \multirow{2}{*}{$\begin{array}{l}P \text {-value } \\
0.57 \mid \\
0.328 \\
0.602\end{array}$} & \multirow[t]{2}{*}{ AOR } & \multirow[t]{2}{*}{$95 \% \mathrm{Cl}$} & \multirow[t]{2}{*}{$P$-value } \\
\hline Age $G$ & $\begin{array}{l}<18 \\
18-28 \\
29-39 \\
40-50 \\
>50\end{array}$ & & & & & & & & \\
\hline Sex & $\begin{array}{l}\text { Male } \\
\text { Female }\end{array}$ & $\begin{array}{l}195 \\
162\end{array}$ & $\begin{array}{l}17 \\
13\end{array}$ & $\begin{array}{l}1.09 \\
1\end{array}$ & $0.5 I-2.30$ & 0.829 & & & \\
\hline Education & $\begin{array}{l}\text { Illiterate } \\
\text { Read \& write } \\
\text { Elementary } \\
\text { Secondary } \\
\text { College, above }\end{array}$ & $\begin{array}{l}148 \\
74 \\
125 \\
25 \\
15\end{array}$ & $\begin{array}{l}16 \\
4 \\
8 \\
2 \\
0\end{array}$ & $\begin{array}{l}1.4 \\
0.66 \\
0.79 \\
1 \\
-\end{array}$ & $\begin{array}{l}0.30-6.47 \\
0.11-3.83 \\
0.16-3.94\end{array}$ & $\begin{array}{l}0.672 \\
0.640 \\
0.770\end{array}$ & & & \\
\hline Occupatn & $\begin{array}{l}\text { Farmer } \\
\text { Gov. employee } \\
\text { Merchant } \\
\text { Others* }\end{array}$ & $\begin{array}{l}131 \\
10 \\
8 \\
138\end{array}$ & $\begin{array}{l}12 \\
0 \\
1 \\
13\end{array}$ & $\begin{array}{l}0.73 \\
- \\
1 \\
0.75\end{array}$ & $\begin{array}{l}0.08-6.36 \\
0.09-6.50\end{array}$ & $\begin{array}{l}0.531 \\
0.797\end{array}$ & & & \\
\hline Residence & $\begin{array}{l}\text { Urban } \\
\text { Semi urban } \\
\text { Rural }\end{array}$ & $\begin{array}{l}124 \\
16 \\
217\end{array}$ & $\begin{array}{l}14 \\
0 \\
16\end{array}$ & $\begin{array}{l}1 \\
- \\
1.53\end{array}$ & $0.72-3.24$ & 0.266 & & & \\
\hline Treatment & $\begin{array}{l}\text { New } \\
\text { Prev treated }\end{array}$ & $\begin{array}{l}298 \\
59\end{array}$ & $\begin{array}{l}8 \\
22\end{array}$ & $\begin{array}{l}1 \\
0.72\end{array}$ & $0.03-0.17$ & 0.000 & 9.94 & $3.73-26.5$ I & $<0.001$ \\
\hline Contact & $\begin{array}{l}\text { No } \\
\text { Yes }\end{array}$ & $\begin{array}{l}284 \\
73\end{array}$ & $\begin{array}{l}29 \\
1\end{array}$ & $\begin{array}{l}1 \\
7.45\end{array}$ & $0.99-55.63$ & 0.05 & 0.18 & $0.22-1.43$ & 0.103 \\
\hline Dol* & $\begin{array}{l}<\mathrm{Imo} \\
\mathrm{I}-2 \mathrm{mo} \\
>2 \mathrm{mo}\end{array}$ & $\begin{array}{l}122 \\
180 \\
55\end{array}$ & $\begin{array}{l}3 \\
12 \\
15\end{array}$ & $\begin{array}{l}I \\
0.09 \\
0.24\end{array}$ & $\begin{array}{l}0.025-0.32 \\
0.11-0.55\end{array}$ & $\begin{array}{l}0.000 \\
0.001\end{array}$ & $\begin{array}{l}1.89 \\
2.42\end{array}$ & $\begin{array}{l}0.48-7.38 \\
0.55-10.60\end{array}$ & $\begin{array}{l}0.362 \\
0.241\end{array}$ \\
\hline NS* & $\begin{array}{l}\text { Severely UN } \\
\text { Moderately } \\
\text { Mildly } \\
\text { Normal } \\
\text { Overweight }\end{array}$ & $\begin{array}{l}34 \\
47 \\
110 \\
193 \\
3\end{array}$ & $\begin{array}{l}3 \\
6 \\
14 \\
7 \\
0\end{array}$ & $\begin{array}{l}2.57 \\
3.89 \\
3.88 \\
1 \\
-\end{array}$ & $\begin{array}{l}0.63-10.48 \\
1.24-12.18 \\
1.51-9.92\end{array}$ & $\begin{array}{l}0.188 \\
0.020 \\
0.005\end{array}$ & $\begin{array}{l}2.95 \\
3.41 \\
3.15\end{array}$ & $\begin{array}{l}0.61-14.20 \\
0.98-11.92 \\
1.13-8.81\end{array}$ & $\begin{array}{l}0.176 \\
0.550 \\
0.029\end{array}$ \\
\hline HIV status & $\begin{array}{l}\text { Negative } \\
\text { Positive }\end{array}$ & $\begin{array}{l}374 \\
30\end{array}$ & $\begin{array}{l}27 \\
3\end{array}$ & $\begin{array}{l}1 \\
0.76\end{array}$ & $0.22-2.66$ & 0.667 & & & \\
\hline
\end{tabular}

Abbreviations: Dol*, duration of illness before medical treatment; NS*, nutritional status.

with the amount of information extracted from the study participants. However, for those who did not complete the treatment, the reason for quitting treatment could be poor socio-economic status as indicated by the fact that $65 / 107$ (62\%) of them were under-nourished and may not afford treatment cost even if they get drugs for free. This may force them to quit drug treatment particularly after the intensive phase (the first 2 months of treatment) when major symptoms could subside without being cured. The other possibility is that some, $13 / 107(12.6 \%)$, of them resort to traditional medicine after starting proper anti-TB drugs for the same reason stated above or other reasons like side-effects of the drugs. There is also a possibility of missing drug resistant TB cases because not all patients undergo DST at the first visit of their medical consultation. Otherwise, there is no evidence of sub-standard treatment regimen in Oromia. The significance of this proportion of previously treated cases could entail addressing problems related to default from treatment. The importance to address different aspects of the diseases encompassing 
Table 6 Comparison of MDR and Non-MDR Within Groups of Selected Variables $(n=387)$, Oromia, 2020

\begin{tabular}{|c|c|c|c|c|c|}
\hline \multicolumn{2}{|c|}{ Characteristics } & \multirow{2}{*}{$\begin{array}{l}\begin{array}{l}\text { Total } \\
\text { N (\%) }\end{array} \\
45(\mid 1.6) \\
172(44.4) \\
92(23.8) \\
5 \mid(\mid 3.2) \\
27(7.0)\end{array}$} & \multirow{2}{*}{$\begin{array}{l}\text { MDR } \\
\mathbf{N}(\%) \\
0(0) \\
15(8.7) \\
10(10.9) \\
3(5.9) \\
2(7.4)\end{array}$} & \multirow{2}{*}{$\begin{array}{l}\text { Non-MDR } \\
\text { N (\%) } \\
45(12.6) \\
157(91.3) \\
82(89.1) \\
48(94.1) \\
25(92.6)\end{array}$} & \multirow{2}{*}{$\begin{array}{l}P \text {-value } \\
0.239\end{array}$} \\
\hline Age & $\begin{array}{l}<18 \\
18-28 \\
29-39 \\
40-45 \\
>50\end{array}$ & & & & \\
\hline Sex & $\begin{array}{l}\text { Male } \\
\text { Female }\end{array}$ & $\begin{array}{l}212(54.8) \\
175(45.2)\end{array}$ & $\begin{array}{l}17(8.0) \\
13(7.4)\end{array}$ & $\begin{array}{l}195(92.0) \\
162(92.6)\end{array}$ & 0.829 \\
\hline Zones & $\begin{array}{l}\text { North Shewa } \\
\text { South-West Shewa } \\
\text { East Shewa } \\
\text { Arsi } \\
\text { West Arsi } \\
\text { Bale } \\
\text { Guji } \\
\text { Borena } \\
\text { West Harerge }\end{array}$ & $\begin{array}{l}31(8.0) \\
26(6.7) \\
68(17.6) \\
83(21.4) \\
22(5.7) \\
46(11.9) \\
58(15.0) \\
23(5.9) \\
30(7.8)\end{array}$ & $\begin{array}{l}2(6.5) \\
1(3.8) \\
5(7.4) \\
3(3.6) \\
5(22.7) \\
5(10.9) \\
4(6.9) \\
0(0) \\
5(16.7)\end{array}$ & $\begin{array}{l}29(93.5) \\
25(96.2) \\
63(92.6) \\
80(96.4) \\
17(77.3) \\
41(89.1) \\
54(93.1) \\
23(100) \\
25(83.3)\end{array}$ & $0.067^{*}$ \\
\hline Residence & $\begin{array}{l}\text { Urban } \\
\text { Semi-urban } \\
\text { Rural }\end{array}$ & $\begin{array}{l}138(35.7) \\
16(4.1) \\
233(60.2)\end{array}$ & $\begin{array}{l}14(10.1) \\
0(0) \\
16(6.9)\end{array}$ & $\begin{array}{l}124(89.9) \\
16(100) \\
217(93.1)\end{array}$ & 0.259 \\
\hline BCG & $\begin{array}{l}\text { Not Vaccinated } \\
\text { Vaccinated } \\
\text { Unknown }\end{array}$ & $\begin{array}{l}280(72.4) \\
95(24.5) \\
12(3.1)\end{array}$ & $\begin{array}{l}28(10) \\
2(2.1) \\
0(0)\end{array}$ & $\begin{array}{l}252(90) \\
93(97.9) \\
12(100)\end{array}$ & 0.027 \\
\hline
\end{tabular}

Note: *Fisher's exact test.

the host and pathogen features, the need for tailored treatment regimens, as well as the needs to further implement an adequate follow-up based on the available resources are important areas to consider. ${ }^{31,32}$

The association between a nutritional status below normal and development of resistance to anti-TB drugs could be attributed to the fact that under-nutrition weakens the immunity of the patients ${ }^{33}$ which can negatively affect the synergetic effect of drugs and nutrition to fight against the $M$. tuberculosis organisms. With the advancement of control programs addressing factors contributing to the development of drug resistance there will be more achievement in prevention and increased treatment success rate for "End TB strategy" to be effective.

The significant difference in developing MDR-TB between those having a history of BCG vaccination and not vaccinated in favor of those vaccinated could be due to the cumulative effect of multiple immune components on the control of mycobacterial growth as a result of vaccineinduced bacterial growth inhibition in combination with drug treatment following historical BCG vaccination. ${ }^{34,35}$
The new anti-tuberculosis drugs are a real hope for the management of drug resistant TB and other new therapeutic combinations which address psychosocial and economic aspects of the disease may improve treatment success rate. ${ }^{36}$

\section{Limitations}

LPA used for DST does not cover all the anti-TB drugs and of course it has a lower resolution compared to conventional methods.

\section{Conclusion}

The findings from DST indicate that the proportion of MDR and the fact that W. Arsi and W. Harerge were at risk of transmission of XDR-TB warrant great attention of the control program holders though it has to be verified through conventional DST.

\section{Abbreviations}

APHRL, Adama Public Health Research Laboratory; AOR, adjusted odd's ratio; $\mathrm{CI}$, confidence interval; COR, crude odd's ratio; DNA, deoxyribonucleic acid; DST, drug 
sensitivity testing; FDRE, Federal Democratic Republic of Ethiopia; FMOH, Federal Ministry of Health; LJ, Lowenstein Jensen; LPA, line probe assay; MGIT, mycobacterial growth indicator tube; MDR, multidrug resistant; MTB, Mycobacterium tuberculosis; NTM, non-tubercular mycobacteria; PCR, polymerase chain reaction; RR, rifampicin resistance; TB, tuberculosis; WHO, World Health Organization; XDR, extensively drug resistant; ZN, Ziehl-Neelsen.

\section{Data Sharing Statement}

The data are available and can be presented by corresponding author on legitimate request.

\section{Ethics Approval}

Ethical clearance was obtained from Health Studies Higher Degree Committee of University of South Africa (Ref No: REC-012714-039, HSHDC/454/2015). The purpose of the study was explained to the study participants and written consents were obtained from each. For those aged less than 18 years, assents were obtained from their parents/guardians in accordance with the Declaration of Helsinki. $^{37}$

\section{Acknowledgment}

The authors are grateful to Adama Public Health Research Laboratory and Quality Assurance Center not only to allow conducting the laboratory work but also for their support of all the required materials and Madda Walabu University for its financial support to transport samples.

\section{Disclosure}

The authors report no conflicts of interest in this work.

\section{References}

1. World Health Organization. Global Tuberculosis Report. Geneva: WHO; 2014.

2. World Health Organization. Global Tuberculosis Report. Geneva: WHO; 2019.

3. Federal Ministry of Health. Guideline for Program and Clinical Management of Drug Resistant Tuberculosis. 2nd ed. Addis Ababa: FMoH; 2014.

4. Federal Ministry of Health. National Guidelines for Management of Tuberculosis, Drug Resistant-Tuberculosis and Leprosy in Ethiopia. 6th ed. Addis Ababa, Ethiopia: FMoH; 2017.

5. Canetti D, Riccardi N, Martini M, et al. HIV and tuberculosis: the paradox of dual illnesses and the challenges of their fighting in the history. Tuberculosis. 2020;122:101921. doi:10.1016/j.tube.2020.10 1921

6. Martin A, Portaels F. Drug Resistance and Drug Resistance Detection, in Tuberculosis 2007 from Basic Science to Patient Care. 1st ed. Palomino JC, Leão SC, Ritacco V editors. Belgium, Brazil, Argentina: Bourcillierkamps.com; 2007:635-660.
7. World Health Organization. Global Tuberculosis Report. Geneva: WHO; 2011.

8. World Health Organization. Global Tuberculosis Report. Geneva: WHO; 2012.

9. World Health Organization. Global tuberculosis report. Geneva. WHO.2013. Available from: http://www.who.int/iris/bitstream/ 10665/91355/1/9789241564656eng.pdf. Accessed July 20, 2015.

10. World Health Organization. Companion Handbook to the WHO Guidelines for the Programmatic Management of Drug-Resistant Tuberculosis. Geneva: WHO; 2014b.

11. World Health Organization. The end TB strategy: the essentials. Geneva: WHO; 2015. Available from:https://www.who.int/tb/publica tions/2015/end_tb_essential.pdf. Accessed March 10, 2020.

12. World Health Organization. Global tuberculosis report. Geneva: WHO; 2018. Available from: https://apps.who.int/iris/handle/10665/ 274453. Accessed November 26, 2019.

13. Pang Y, Zhou Y, Zhao B, Liu G, Jiang G. Spoligotyping and drug resistance analysis of Mycobacterium tuberculosis strains from national survey in China. PLoS One. 2012;7(3):e32976. doi:10.13 71/journal.pone.0032976

14. Tessema B, Beer J, Marker M. Molecular epidemiology and transmission dynamics of Mycobacterium tuberculosis in Northwest Ethiopia: new phylogenetic lineages found in Northwest Ethiopia. BMC Infect Dis. 2013;13(1):131. doi:10.1186/1471-2334-13-131

15. Federal Ministry of Health. Tuberculosis, Leprosy, and TB/HIV Prevention and Control Program Manual. 4th ed. Addis Ababa, Ethiopia: FMoH; 2008:30.

16. Federal Democratic Republic of Ethiopia. The National Standard Operating Procedures for Biological Sample Transportation. Addis Ababa, Ethiopia: FDRE; 2014.

17. World Health Organization. Laboratory Services in Tuberculosis Control: Microscopy Part II for the Global Tuberculosis Program. Geneva: WHO; 1998a.

18. World Health Organization. Laboratory Services in Tuberculosis Control: Culture Part III. For the Global Tuberculosis Program. Geneva: WHO; 1998b.

19. Tauns Laboratories, Inc. CapilaTM TB-Neo version 6.0. Available from: https://www.goffinmoleculartechnologies.com/wp-content/ uploads/2018/11/IFU_capilia_tb-neo_packageinsert_c61.pdf. Accessed April 27, 2021.

20. Hain-Lifescience GmbH. GenoType MTBDRplus 2.0 product. Available from: https://www.ghdonline.org/uploads/MTBDRplusV2 0212_304A-02-02.pdf. Accessed March 31, 2019.

21. Hain-Lifescience GmbH. GmbH GenoType MTBDRsl 2.0 product. Available from: https://www.immunodiagnostic.fi/wp-content /uploads/MTBDRsl-V2_kit-insert.pdf. Accessed March 31, 2019.

22. Tripathi R, Anupurba S. Multidrug - resistant tuberculosis detection and characterisation of mutations in Mycobacterium tuberculosis by genotype MTBDRplus. Indian J Pathol Microbiol. 2017;60 (2):239-242. doi:10.4103/IJPM.IJPM $53 \quad 16$

23. Brhane M, Kebede A, Petros Y. Molecular detection of multidrugresistant tuberculosis among smear-positive pulmonary tuberculosis patients in Jigjiga town, Ethiopia. Infect Drug Resist. 2017;10:75. doi:10.2147/IDR.S127903

24. Tadesse M, Aragaw D, Dimah B, et al. Drug resistance-conferring mutations in Mycobacterium tuberculosis from pulmonary tuberculosis patients in Southwest Ethiopia. Int J Mycobacteriol. 2016;5 (2):85-191. doi:10.1016/j.ijmyco.2016.02.009

25. Tamrat F. Molecular Epidemiology and Drug Sensitivity of Mycobacterium Tuberculosis Isolates among New Pulmonary Tuberculosis Patients in Arsi Zone Oromiya Region, Ethiopia (Doctoral dissertation). Addis Ababa University; 2016.

26. Diriba G, Kebede A, Tola HH, et al. Surveillance of drug resistance tuberculosis based on reference laboratory data in Ethiopia. Infect Dis Poverty. 2019;8(1):54. doi:10.1186/s40249-019-0554-4 
27. Wondale B, Medhin G, Abebe G, et al. Phenotypic and genotypic drug sensitivity of Mycobacterium tuberculosis complex isolated from South Omo zone, Southern Ethiopia. Infect Drug Resist. 2018;11:1581-1589. doi:10.2147/IDR.S165088

28. Tessema B, Beer J, Emmrich F, Sack U, Rodloff AC. First- and second-line antituberculosis drug resistance in Northwest Ethiopia. Int J Tuberc Lung Dis. 2012;16(6):805-811. doi:10.5588/ijtld.11.0522

29. Yonge SA, Otieno MF, Sharma RR, Nteka SS. Drug susceptibility patterns of Mycobacterium tuberculosis isolates from tuberculosis patients in coastal Kenya. $J$ Tuberc Res. 2017;5(4):201-219. doi:10.4236/jtr.2017.54022

30. Sabeel S, Salih MA, Ali M, et al. Phenotypic and genotypic analysis of multidrug-resistant Mycobacterium tuberculosis isolates from sudanese patients. Tuberc Res Treat. 2017;2017:1-6. doi:10.1155/ 2017/8340746.

31. Riccardi N, Alagna R, Saderi L, et al. Towards tailored regimens in the treatment of drug-resistant tuberculosis: a retrospective study in two Italian reference centres. BMC Infect Dis. 2019;19(1):1-9. doi:10.1186/s12879-019-4211-0

32. Riccardi N, Villa S, Alagna R, et al. Advantages and challenges of tailored regimens for drug-resistant tuberculosis: a stopTB Italia look into the future. Infect Drug Resist. 2020;13:2795-2800. doi:10.2147/ IDR.S257480 PMID: 32848428; PMCID: PMC7429110.
33. World Health Organization. Guideline: Nutritional Care and Support for Patients with Tuberculosis. Geneva, Switzerland: WHO; 2013.

34. Fletcher HA, Tanner R, Wallis RS, et al. Inhibition of mycobacterial growth in vitro following primary but not secondary vaccination with Mycobacterium bovis BCG. Clin Vaccine Immunol. 2013;20 (11):1683-1689. doi:10.1128/CVI.00427-13

35. Kashongwe IM, Mawete F, Mbulula L, et al. Outcomes and adverse events of pre-and extensively drug-resistant tuberculosis patients in Kinshasa, Democratique Republic of the Congo: a retrospective cohort study. PLoS One. 2020;15(8):e0236264. doi:10.1371/journal. pone. 0236264

36. Villa S, Riccardi N, Canetti D, et al. From the past a long way to future Challenges for a great control of tuberculosis. Tuberculosis. 2020; 123:101948.

37. World Medical Association. World Medical Association Declaration of Helsinki: ethical principles for medical research involving human subjects. JAMA. 2013;310(20):2191-2194. PMID: 24141714. doi:10.1001/jama.2013.281053
Infection and Drug Resistance

\section{Publish your work in this journal}

Infection and Drug Resistance is an international, peer-reviewed openaccess journal that focuses on the optimal treatment of infection (bacterial, fungal and viral) and the development and institution of preventive strategies to minimize the development and spread of resistance. The journal is specifically concerned with the epidemiology of
Dovepress

antibiotic resistance and the mechanisms of resistance development and diffusion in both hospitals and the community. The manuscript management system is completely online and includes a very quick and fair peerreview system, which is all easy to use. Visit http://www.dovepress.com/ testimonials.php to read real quotes from published authors. 